\title{
A Semiotic Analysis of Cyber Emoticons (A Case Study of Kaskus Emoticons in the Lounge Forum at Kaskus-the Largest Indonesian Community)
}

\author{
Didi Sukyadi \\ Sri Setyarini \\ Ade Irma Junida \\ English Education Department, Faculty of Language and Arts Education, Indonesia \\ University of Education, Dr. Setiabudhi 229, Bandung 40154, Indonesia \\ e-mails: didisukyadi@live.com \\ englishupi@yahoo.co.id \\ jujunida@gmail.com
}

\begin{abstract}
Kaskus emoticons have been used widely in cyber, whether in Kaskus forum or blogs and other Instant Messengers (IMs). The use of emoticon in the forum is believed to be the latest way in communication among members. The use of emoticons is necessary to overcome the constraints of online communication, the need of being expressive and time limited. Kaskus emoticons are culturally unique because they are created by Indonesian online users without resorting to western style emoticons. Even though emotion is something universal, the way of how certain community represents it through emoticons is interesting to note. This study is aimed at exploring the significance of Kaskus emoticons in the Lounge forum at Kaskus, the Largest Indonesian Community. The analysis is rooted on semiotics, particularly Roland Barthes' orders of signification involving five emoticons appearing in the Lounge forum at the site. The findings show that the emoticons have meaning and functions as a way to communicate, particularly in the online forum. It serves as a means of (visual) communication between users to emphasize the statement in online communication, and to show mood of one's state of feeling so that others can easily acquaint his thoughts. More to the point, emoticons are treated as alteration for some words and their meanings are associated with linked circumstances.
\end{abstract}

Key words: semiotics, Kaskus, emotion, icon, emoticon, Kaskus emoticon 
Nowadays, internet has developed into an effective and global media as a communication tool. Instant messaging, chat rooms, and personal web sites increase its occurrences in cyber; making the media where people can keep in touch with others around the world and get information and entertained. One of the most crucial elements in cyber is the deployment of images because according to Nugroho (2010), words alone fail to convey meaning completely. The nature communication on the internet allows people to express their thoughts and feelings by using image that represents their mood or facial expression. The image is called as emoticon, which is often used for stressing the statement particularly in online communication and alerting the respondents to the tone or mood of the statement makers.

Emoticon is used to conpensate the drawbacks of online communication, which will not be effective when using words only. Different from other communication models, online communication is usually quite compact and brief with much information to include but at the same time the users need to be as effective and as expressive as possible. Lawson and Leck (2006) observe that emoticon is used to compensate the lack of non verbal and para verbal cues. It is used to establish close relationship within the constraint of the Internet, to identify online users as cool and trustworthy, and to tweed out people who do not share others' realities or ways of being (Waskul, 2003 as cited by Lawson \& Leck, 2006). Emoticon is used as alternatives to non verbal gestures such as demure glances and eyebrow flashes which are not easily replicated online (Whitty, 2003). Emoticons are also often used in the text-based online communication to convey feelings or to demonstrate facial expressions such smiles or frowns (Mallen, David, Vogel, \& Rochlen, 2005).

Noticed from the official website Kaskus-The Largest Indonesian Community: Kaskus Forum-Online Community \#1 for Indonesian Community, Kaskus has two main forums on it; namely custom forum and trading forum. Each forum has its own sub-forums with their typical characteristics, from ordinary thing until the extraordinary one. The custom forum is divided into several sub-forums where the user-which is called "kaskuser", shares everything. Based on observation among the kaskusers, the most popular forum is CAS-CIS-CUS, in which the kaskusers there can share anything, from the latest news and gossips to their problems. Since CAS-CIS-CUS has reached the highest rank as the most visited forum in Kaskus, the present study is focused on the Lounge forum which is part of the CAS-CIS-CUS forum. The Lounge is a forum which shares jokes, stories, news and information about everything. In the Lounge, the 
communication between TS (Thread Starter, the one who creates the topic) and other users varies in many ways, from praising to insulting. Their communication is not only through language but also through images, in this case the typical emoticons that makes the forum interesting to follow.

There are at least three reasons why why studying Kaskus emoticons will reveal something significant. Firstly, Kaskus emoticon has been used widely in cyber. Kaskus forum, along with its slogan-the Largest Indonesian Community, is an internet forum site which has grown to be one of the most popular websites in Indonesia and has been considered as the largest Indonesian online community since its members reach over one million in April 2010. The community contains many people coming from various backgrounds, with different occupations, gender and age. Secondly, in Kaskus, the available emoticons are different from other forums. It has its own characteristics and the members of the forum use it mostly as a language of communication. Today, Kaskus emoticons are used not only in Kaskus forum but also in some blogs, and other instant messengers due to their simple installation. On the other hand, many of kaskuser and bloggers use Kaskus emoticons to show how proud they are of being Indonesian because Kaskus emoticon is originally made by Indonesian.

Furthermore, the use of Kaskus emoticon is a phenomenon that happens almost every time either in Kaskus or in other forums. It is believed that anything can be used as a language like what the Kaskus emoticons do in the forum. The employed emoticons function as a means of communication and interacting among each other, visually in particular. Therefore, the practice is called a visual communication. The term emoticon which is derived from two words: emotions and icon, is a language realized in the form of images. It is considered that image is also a sign and can be interpreted as something else because of similarity in characteristics; hence semiotics or semiology is applied to explore the meaning behind things. This paper is aimed at analyzing the significance of Kaskus emoticons in the Lounge forum at Kaskus, the Largest Indonesian Community.

\section{EMOTICON}

Scott Elliott Fahlman, a Professor of Computer Science at Carnegie Mellon University introduced the first emoticon used in Internet on September 19, 1982. In his message, Professor Fahlman originally 
suggested the use of this emoticon :-) following funny and humorous posts on the message board and the use of this emoticon :-( for every thing else that was not meant to be funny and all serious remarks. The frowning face emoticons used today are meant as an indication of anger and sadness.

Western style emoticons are written from left to right with eyes on the left followed by the nose and mouth. It can be seen by tilting head towards left shoulders. Asian style emoticons use other symbols to create faces such as this emoticon $\left(*_{-}^{*}\right)$ to show surprise. The asterisks indicate the eyes; the central character, commonly an underscore, the mouth; and the parentheses, and the outline of the face. Two separate studies, in 2007 at Hokkaido University and in 2009 at Glasgow University, show that Japanese and other East Asians read facial expressions by looking mainly at the eyes, and the researchers noted that this is reflected in East Asian emoticons which put emphasis on the eyes, compared to Western emoticons which emote mainly with the mouth (Yuki, Maddux, \& Masuda, 2007).

Emoticon derives from two separate words 'emotion' and 'icon'. Emotion refers to tendency for having special feeling when it is faced with particular object in an environment (James in Wedge, 1995 in Sobur, 2003). Whereas icons are signs whose signifiers take a close resemblance to the things they refer to. According to Pierce, icons are the only means of directly communicating an idea. There are numerous emoticon meanings and the most commonly used are for expressing smiling face and frowning expression. Emoticons are a simple and easy way to convey emotions which would be difficult to portray through the written word. The emoticon then is seen as iconic sign since it resembles the object it represents particularly the implication of the face expression showed. For instance, smiling emoticon ":)" represents happiness although the emoticon itself does not possess physical properties like the object, such as mouth drawn back at corners and raised cheek (just like a smiling man). The emoticon uses colon which is regarded as the eyes and parentheses as the mouth. This is in line with Eco's statement "iconic signs do not possess the same physical properties as do their objects but they rely on the 'same' perceptual structure, or on the same system of relation." (Sukyadi, 2005, p. 54).

Emoticons vary according to their characteristics such as colors and emotions. Color is a complement of image which also connotes psychological condition of its creator. It conveys meanings in two primary ways - natural associations and psychological (cultural) associations. It 
represents connotative meaning and symbols in order to express one's emotion, identities and certain objectives (Wilfred, 1962, Sekarwangi, 2006).

The notion that emotions are linked discretely with facial expressions has roots in the work of Charles Darwin. He claims that facial expressions are the remaining actions of more complete behavioral responses, and occur in combination with other bodily responses - vocal, postural, gestural, skeletal muscle movements, and physiological responses. Facial expression as mimic behavior transmits signals independently of speech, as interactional signals, and facial movements related with phonetic articulation (Nöth, 1990). In accordance with Ekman (2003), basic emotions are divided into these five below.

1. Sadness and agony are unhappy emotions caused by a great loss of something or someone. Agony deals actively with the cause which makes it sort of suffering; meanwhile, sadness is more passive feeling that lasts longer than agony. The facial expression can be seen as mouth open, corners of lips down, raised cheek, eyes look downward and upper eyelids droop.

2. Anger is the face of attack or violence caused by disappointment, frustration, revenge, or when someone hurts physically either to himself or to other that he cares the most. The facial expression can be seen as eyebrows pulled down, eyes wide-open, hard-staring and lips pressed.

3. Surprise and fear often comes in sequence. Surprise lasting only few seconds then merges into fear, amusement, relief, anger, disgust and so forth. It is commonly caused by the threat of harm either physically or psychologically. The facial expression on surprise is eyes wide open, eyebrows raised and jaw drops open. While in fear, eyebrows raised, jaw drops open, upper eyelids raised and straight staring.

4. Disgust and contempt are quite similar emotion but differ in intention. Disgust is a feeling of aversion, not only to tastes, smells, touches or thought, but also to actions and appearance of people or even ideas. The facial expression seen as nose wrinkling, upper lip raised and eyebrows pulled down. Contempt is related to disgust but in a lighter intention. The expression is on one side of the face which corner lip tightened and slightly raised.

5. Enjoyable emotions such as pleasure, amusement, excitement, relief, wonder and ecstasy has an expression of cheek pushes up, mouth drawn back at corners and wrinkled skin under the eyes. 


\section{BARTHES' ORDERS OF SIGNIFICATION}

Semiotics is applied as a way to analyze the significance of Kaskus emoticons in the Lounge forum at Kaskus, the Largest Indonesian Community. The emoticons are seen as a means of communication in the forum. Each emoticon is analyzed using Barthes' semiology and labeled its orders of signification consisting of denotation, connotation and myth to discover the meaning behind the emoticons. Denotation as the first order of signification contains a signifier and a signified, meanwhile connotation is the second order of signification which uses denotative sign as its signifier and relates it to additional signified. This makes denotation as the basic and primary meaning of a sign.

According to Barthes, in the level of denotation, the existing social codes are explicit, meaning that the significance of codes is seen on its surface based on the relationship of the signified and the signifier. On the other hand, in the level of connotation the codes are implicit and hidden. This hidden meaning lies in the area called ideology or mythology, as he claimed (Piliang, 2003). Mythology or myth sees meaning in deeper rate yet much more conventional. On his viewpoint, myths help us to make sense of our experiences within a culture. They express and serve the ideological function of naturalization. Their function is to make dominant cultural and historical values, attitudes and beliefs seem entirely "natural", "normal", self-evident, timeless, obvious "common-sense" - and thus objective and "true" reflections of "the way things are" (Chandler, 2002, p. 145). Barthes (1957) proposes that myth is a second order in semiotic system which is built on the principle of connotation. It is applied to "naturalize" the messages at denotational level as a vehicle for connotational meaning. Further, he suggested that myth is a way of coding the meaning and social value (which is essentially arbitrary or connotative) as something natural.

\section{METHODS}

The emoticons employed in this study were those which can be found solely in Kaskus, the Largest Indonesian Community. The typical emoticons are divided into big and small emoticons. Since the small one is similar to the big one, this study employed only big typical emoticons which frequently appear in the Lounge forum in Kaskus, the Largest 
Indonesian Community. Ahead of time, most of the emoticons were in the form of animated GIF (Graphics Interchange Format). It is a bitmap image format that was introduced by CompuServe in 1987 and has since come into widespread usage in the World Wide Web due to its wide support and portability (Heim \& Sinha, 2001; Ballard, Joseph, \& McKenzie, 2002). GIF was one of the first image formats commonly used in web sites and nearly all emoticons are animated; meaning that it is moveable and has duration of moving.

As noted previously, those emoticons are analyzed using Barthes' orders of signification comprises of first order signification (denotation), second order signification (connotation) and myth as a way to naturalize the connotational meaning. The denotation then is seen based on psychological theory which sees the elements of the selected emoticons and how the connotation is attached to it. In addition, the connotation analyzed through cultural values and myth is interpreted by the observer's viewpoint. The interpretations are expanded based on the local and global meaning; both in Kaskus, the Largest Indonesian (Online) Community and global use.

\section{FINDINGS AND DISCUSSION}

This section presents the results from the analysis of the selected emoticons classified from basic human emotions proposed by Ekman (2003).

a. Sadness and agony

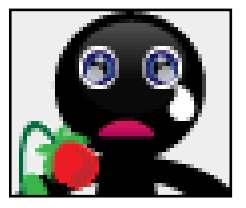

The emoticon that represents sadness and agony in the Lounge forum at Kaskus, the Largest Indonesian Community is "berduka" emoticon. In the first order signification, "berduka" emoticon portrays a man in black color with tear(s) while holding a wilted red rose. The visual descriptions of the man in black color with openedeyes full of tears and upper lip descend connote sad expression. In the meantime, tear drops signifies crying and wilted red rose shows a great loss and sadness. Red rose is used for giving empathy - especially in funeral, while the wilted red rose indicates a great sorrow like a red rose which gets weaker and wilt.

Black is a color which is characterized by the absence of light and therefore denotes darkness, mystery, grief, sorrow and melancholy. It is 
associated to Western culture that uses black in funeral clothes and other matters related to death. Literarily, the phrase black mood supports this statement. Simultaneously, it also has the connotation of formality and stateliness. The black suit and dress are both the favorite traditional clothes for the Westerners. Along the lines, Wilfred (1962) and Sekarwangi (2006) state that black connotes formality, darkness, magic, mystery, grief, artist and elegance.

In contrast, Chinese assume that black denotes strength and authority; it is considered to be a very formal, elegant, and prestigious color. The black color is the Emperor's unique color of the clothes; the common people are not allowed to wear the black clothes (He, 2009). On serious occasions, all celebrities like black clothes; all the members of the symphony orchestra are all in black suit to show the respect to the audience which then emphasizes the elegance of the color.

In Kaskus, the Largest Indonesian Community, specifically in the Lounge forum, "berduka" emoticon is commonly used to show and emphasize sympathy and sorrow particularly in posts about miserable stories. This is in line with the term "berduka" which is translated as condolence in English which is used to show condolence and sorrow. To conclude, this emoticon describes someone who gives sympathy or condolence represented by black color, cry and a wilted red rose.

b. Anger

"Marah" emoticon is one of Kaskus emoticons which contribute anger emotion in its characteristics. "Marah" (translated as anger in English) is one of several emoticons in Kaskus forum that represents anger emotion. Based on the

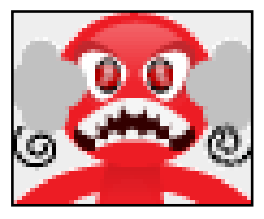
first order signification, the emoticon describes a red person with redeyed wide open, eye-brows raised, visible fang, and smoke comes out of the nose. This facial expression represents anger. It is in consideration that when someone gets mad, his face looks like a horrible opened-mouth monster with big fangs.

In this emoticon, red color signifies strong and anger. Being the color used by traffic control systems in stop signs and traffic lights, red is connoted to be strong and powerful. While anger is signified by the color when people are described as turning red, in case others see redas blood rushes to the face. However, Chinese assume red as happiness and joyous meaning. It is the color of good luck and is used for 
decoration and in wedding dressing; the brides always wear a red $Q i$ $P a o$ or a red wedding dress at wedding ceremony because the color stands for propitious sign (He, 2009).

Sukyadi (2006) notes that anger can be caused directly by others, e.g. being offended, insulted and unappreciated. Frustrated, revenge, resentment and dislike may also trigger anger. In Kaskus, specifically the Lounge forum, the "marah" emoticon is usually used when someone feel irritated over someone or something. The emoticon mostly used to shows anger about someone or something which is posted in a thread. It is also a way to show anger to the TS (thread starter, the one who creates a topic) and other kaskusers. To conclude, "marah" emoticon represents anger through the red face, smoke and angry expression.

c. Surprise and fear

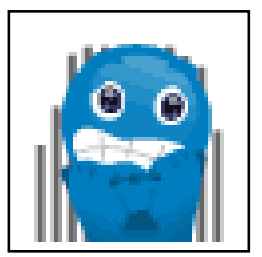

"Takut" emoticon is an emoticon which characterizes, particularly owing to its basic emotion, fear. The analysis and its explanation is described as follows. In the first order signification the emoticon portrays a man in blue color who looks terrified about something. "Takut" is translated as frightened; a feeling or state of fear. It is a reaction which appears after seeing or hearing horrifying things. This emoticon is basically used to show how frightened someone is because of something, particularly horrifying things such ghosts or bad things. This emoticon also describes other characteristics when these feelings aroused such as trembling, fast heartbeat, pale and shiver. Vertical lines behind the blue character show shiver. Moreover, the blue character looks like he is biting his hand as a way for showing a state of anxiety. As a result, chattering teeth is known to be a reaction for frightened. Wilfred (1962) and Sekarwangi (2006) state that blue represents wisdom, honesty, intensity, power, constructive, sincerity, cooperative, and integrative. However, blue color in the emoticons analyzed signifies honesty for affirming the state of fear. Blue as honesty is represented by pharmaceutical products and corporate logos that use it as the basic color. Honesty gives trust that creates a cooperative response both to the company and to its products.

In Kaskus, particularly in the Lounge forum, the emoticon is basically used to emphasize a state of fear because of horrifying things such as 
ghosts as well as bad and scary stories. Kaskusers often use the emoticon not only for expressing their moods and feelings but also for stating fear and replacing the word "takut".

d. Disgust and contempt

This emoticon obviously shares disgust feeling in the green character. In the first order signification, "najis" emoticon employs "maho" character as it is used in hoax emoticon for stressing the intention of disgusting feeling. "Najis", translated as disgust in English, is an Islamic term originated from Arabic

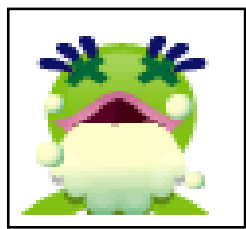
which means things or persons regarded as ritually unclean. In Indonesia, dirty things, words and even persons are usually considered as "najis". For this reason, the emoticon displays "maho" character who is throwing up.

Additionally, maho, which stands for manusia homo (translated as gay in English) is a character that portrays green colored man with over make-up face. The character is dedicated to annoying person or someone whose appearance looks like a gay. In the first order signification, maho character depicts a man in green color and over make-up face. This appearance causes a feeling of disgust as well as a maho (gay). Although many countries consider gay as normal, Indonesian culture sees it as a contradictive, that most people would judge it despicably and poisonous. This impression is reflected from the green color of the character (as well as the najis emoticon). The combination is used to express hatred feeling toward something or someone in the Lounge forum at Kaskus, the Largest Indonesian Community.

Green color in this emoticon signifies poison and wickedness. It implies a disgusting feature of something bad and lies. This is in line with Wilfred (1962) and Sekarwangi (2006) who say that green connotes envious, poison and wickedness. Some villains in superhero cartoons are characterized with the green color such as Green Goblin in Spiderman and Buto Ijo (Green Giant) in Indonesian's legend. However, Westerners often relates biliousness, fear and anger with green. Therefore there is a term green-eyed, which usually followed by jealousy (originated from Shakespeare's Merchant of Venice). 
e. Enjoyable emotions

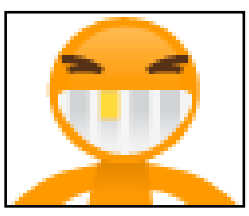

Happiness is an enjoyable emotion which can be seen in almost all emoticons analyzed in this study. This emotion is usually expressed by grin and smile because of pleasure, amusement, excitement, relief, wonder and ecstasy. "Ngakak" emoticon is one example of this category. The analysis is depicted below.

"Ngakak" is translated as laugh or laugh out loud or a lively laugh. It can be aimed at making the sounds and movements of face that shows happiness or thinking that something is funny. In Indonesia, the use of "ngakak" is basically applied in a situation where someone laughs over excitedly about something or someone.

In the first order signification, the emoticon portrays a man in orange color with big grin and closed eyes. Orange is one of the three secondary colors which is formed by mixing red and yellow color. This color also generates another level meaning in mind. Naturally, the orange color is similar to the color of sunshine in the summer which cheers up the day. Sunshine then relates to holidays and happiness. This is in line with Wilfred (1962) and Sekarwangi (2006) who say that orange color connotes happiness, as the facial expression of "ngakak" emoticon.

In Kaskus, the Largest Indonesian Community, specifically in the Lounge forum, the emoticon "ngakak" has been used widely. It is known that the Lounge contains almost every kind of news, gossips, and stories. Moreover, there are many funny things shared in the posts which make other users laugh. Kaskusers who want to share something fun, such as jokes usually use this emoticon. Additionally, the emoticon is used to emphasize a great joy of the jokes or to the story posted.

Concisely, the analysis has been depicted some Kaskus emoticons employing Barthes' orders of signification based on its characteristics. There are five analyzed emoticons in the study: "berduka", "marah", "takut", "najis" and "ngakak" emoticons. Those emoticons have their own characteristics such as various names - usually in Indonesian, colors and facial expressions. Indonesian is chosen as the name for those emoticons because Kaskus forum, along with the slogan: Kaskus, the Largest Indonesian Community, is a forum of Indonesian community of all gender, location and age. It is also exceedingly comfortable for kaskusers to use Indonesian as it is their daily language. 
Other characteristics that hold critical point in Kaskus emoticon are facial signals (emotions) and colors. As it is originated from the words 'emotion' and 'icon', emoticon is built on the basis of those emotions. Happiness, sadness, anger, disgust, surprise and fear are emotions discovered in the analyzed emoticons. The face is the medium of relatively permanent signals in the human physiognomy and of the temporarily variable signals facial expressive movements (Nöth, 1990). For that reason, face transmits thousands of meanings. Gaze, smile or even wrinkle in side of the face can be sensed as something else. For instance, wrinkled skin under eyes and mouth drawn back at corners are signifying happiness as when someone is smiling. However, one-sided gaze can be signified as a way to underestimate others.

In the meantime, the color in those emoticons varies such as red, blue, green, orange and black. Every color designates another level of meaning as it is described by Wilfred (1962) and Sekarwangi (2006). They propose that almost every color denotes symbols in order to express one's emotion, identities and certain objectives that somehow relate to the cultural values. These colors connote meaning from how they are used both visually and verbally. For instance, visually, red color describes fire; nevertheless, for westerners, the term turning red is intended for showing embarrassment and anger.

To be brief, Kaskus emoticons, as have been analyzed in the study, is significantly meant to be used as a way to communicate. Facial signals show emotions which is then used to emphasize the mood and feeling of statement in online communication. Meanwhile, the color in the analyzed emoticons supports the meaning of each emoticon. In such a way, the emoticon that comprises emotion and color wholly creates intention to deliver meaning of the emoticon. Emotion and color are used to emphasize the way emoticon share its meaning. However, both elements are crucial considering that an emoticon would be only a plain image without emotion and color. Additionally, each emoticon which has name (esp. in Indonesian) is also used as an alteration for some words and its meaning, particularly the words (names) in the emoticons. For instance, "ngakak" emoticon is used as alteration for laughing and stating that something is funny. Since "ngakak" emoticon aims at emphasizing laughing, then it is acceptable to use it as an alteration. 


\section{CONCLUSION}

This study has analyzed the significance of cyber emoticon, particularly Kaskus emoticons in the Lounge forum at Kaskus, the Largest Indonesian Online Community. The use of the typical emoticons is believed to be the latest way in communication. Therefore this study is conducted to analyze the significance of those emoticons in related forum.

The investigation concludes that Kaskus emoticons in the Lounge forum serve as a means of (visual) communication among users to emphasize the statement in online communication. It shows mood of one's state of feeling so that others can easily acquaint his thoughts through the emotion and color in each emoticon. More to the point, it is treated as alteration for some words and its meaning associated with linked circumstance. In other words, emoticons are used as a language to communicate something the same way as someone communicates to others without directly facing them. In such a way, emoticons then play a crucial role in communication, specially the visual one, as an alteration of common language.

\section{REFERENCES}

Ballard, K. D., Joseph, G. H., \& McKenzie, D. (2002). Technological facilitation of terrorism: Definitional, legal, and policy issues. American Behavioral Scientist, 45, 989.

Barthes, R. (1972). Mythologies. (J. Cape., Trans.). New York: The Nooday Press. (Original work published 1957).

Chandler, D. (2002). Semiotics the basics. London: Routledge.

Ekman, P. (2003). Emotions revealed. USA: Times Book.

He, G. (2009). English and Chinese cultural connotation of color words in comparison. Asian Social Science, 5(7), 160-163. Retrieved October 5, 2010, from http://ccsenet.org/journal/index.php.ass/article/download/ 985/2754.

Heim, G. R., \& Sinha, K. K. (2001). A product-process matr. 2009: English and Chinese cultural connotation of color words in comparison [Electronic version]. Asian Social Science, 5(7), 160-163. Retrieved October 5, 2110, from http://ccsenet.org/journal/index.php/ass/article/download/2985/2754. 
Lawson, H., \& Leck, K. (2006). Dynamics of internet dating. Social Science Computer Review, 24, 189.

Mallen, M. J., David L., Vogel, D. L., \& Rochlen, A., B. (2005). The practical aspects of online counseling: Ethics, training, technology, and competency. The Counseling Psychologist, 33, 776.

Nöth, W. (1990). Handbook of semiotics. Bloomington: Indiana University Press.

Nugroho, A. D. (2010). Mathematics textbooks of primary 1 used in Singapore: A multimodal analysis of its intersemiosis, $k @ t a, 12(1), 72-91$.

Piliang, Y. A. (2003). Hipersemiotika: Tafsir cultural studies atas matinya makna. [Hypersemiotics: Cultural studies interpretation on the death of meanings]. Bandung: Jalasutra.

Sekarwangi, I. (2006). Cerita bergambar sebagai media pembelajaran [Pictured stories as teaching media]. Unpublished undergraduate thesis, Indonesia University of Education, Jakarta.

Sobur, A. (2003). Psikologi umum. [General psychology]. Bandung: Pustaka Setia.

Sukyadi, D. (2005). Ikonisitas klausa partisipium lepas bahasa Inggris dalam teks naratif dan nonnaratif. [The Iconicity of English detached participle clauses in narrative and non-narrative texts]. Unpublished doctoral dissertation, University of Indonesia, Jakarta.

Sukyadi, D. (2006). Peranan prototipe dalam pendefinisian konsep abstrak "marah" dan "benci". [The role of prototype in defining abstract concepts of "anger" and "hatred"]. Directory of Faculty of Language and Arts Education, Indonesia University of Education [Electronic version]. Retrieved October 5, 2010, from http://file.upi.edu/direktori/c-fpbs/ jur.pend bahasainggris/196706091994031-DidiSukyadi/prototypesofmarahdan benci. pdf

Whitty, M. T. (2003). Cyber-flirting: Playing at love on the internet. Theory and Psychology. Sage Publication, 13(3), 339-357.

Wilfred, T. (1962). Color organ. In Compton's pictured encyclopedia (pp. 235237). Chicago: F. E. Compton \& Company.

Yuki, M., Maddux, W. W., \& Masuda, T. (2007). Are the windows to the soul the same in the East and West? Cultural differences in using the eyes and mouthas cues to recognize emotions in Japan and the United States. Journal of Experimental Social Psychology, 43, 303-311. Retrieved October 5, 2010, from http://faculty.insead.edu/maddux/personal/documents/JESPF acePaper.pdf University Press. 